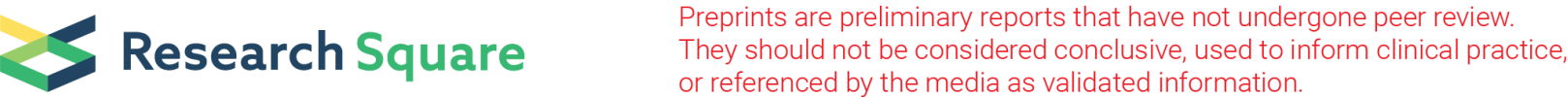

\section{Non-atrial fibrillation was associated with early neurological improvement after intravenous thrombolysis with rt-PA in patients with acute ischemic stroke}

Jie Liu

Zhejiang University School of Medicine Second Affiliated Hospital

Jiaqi Huang

Zhejiang University School of Medicine Second Affiliated Hospital

Huimin Xu

Zhejiang University School of Medicine Second Affiliated Hospital Haibin Dai ( $\square$ haibindai@zju.edu.cn )

Zhejiang University School of Medicine Second Affiliated Hospital https://orcid.org/0000-0002-57682714

\section{Research article}

Keywords: Acute ischemic stroke, Recombinant tissue plasminogen activator, Intravenous thrombolysis, Early neurological improvement

Posted Date: February 22nd, 2019

DOI: https://doi.org/10.21203/rs.2.405/v1

License: (c) (i) This work is licensed under a Creative Commons Attribution 4.0 International License.

Read Full License 


\section{Abstract}

Background To investigate the factors associated with early neurological improvement of intravenous recombinant tissue plasminogen activator (rt-PA) treatment to acute ischemic stroke (AIS) within 4.5 hours of onset. Methods Demographics onset to treatment time, risk factors, and clinical and laboratory data of 209 AlS patients undergoing intravenous rt-PA therapy at the Second Affiliated Hospital, Zhejiang University School of Medicine between January 2013 and August 2016 were retrospectively analyzed. The National Institute of Health Stroke Scale (NIHSS) score was recorded before thrombolytic therapy, 24 $\mathrm{h}$ after the treatment and $7 \mathrm{~d}$ after the treatment to evaluate the recovery of neurological function. A multivariate logistic regression analysis was performed to assess the outcomes. Results Of the 209 AIS patients treated by intravenous thrombolysis with rt-PA. Low-density lipoprotein (LDL) levels were significantly lower $(P<0.05)$ in patients with early neurological improvement. The multivariable analysis showed that non-atrial fibrillation (AF) was independently associated with early neurological improvement at $24 \mathrm{~h}$ and $7 \mathrm{~d}$ after thrombolysis. Onset to treatment time was an independent predictor ( $\mathrm{P}$ $<0.05)$ for early neurological improvement at $7 \mathrm{~d}$ after thrombolysis. The NIHSS score and diastolic blood pressure on admission were associated with symptomatic intracerebral hemorrhagic $(\mathrm{sICH})$ transformation. Conclusions Non-AF was independently associated with early neurological improvement after intravenous thrombolysis in AIS patients, but non-AF was not associated with the occurrence of $\mathrm{sICH}$. Onset to treatment time was an independent predictor of early neurological improvement at $7 \mathrm{~d}$ after thrombolysis in AIS patients.

\section{Background}

Stroke is the leading cause of death in the world, and more than $80 \%$ of strokes are ischemic $[1,2]$. Stroke has become a huge economic burden for both the families of the victims and society. Intravenous thrombolysis is the only approved pharmacological treatment for acute ischemic stroke (AIS) patients. The benefit of rt-PA was thought to be due to vessel recanalization, resulting in restitution of blood flow to ischemic regions of brain, which improves neurological outcomes of stroke patients treated with intravenous rt-PA within $4.5 \mathrm{~h}$ from symptoms onset [3]; however, only approximately $50 \%$ of AIS patients show significant improvement after thrombolytic therapy [4, 5]. Some studies have shown that early improvement of neurological function after intravenous thrombolysis was an independent predictor of better prognosis at 90 days [6-8], while other studies have identified diverse predictors of major neurological improvement 24 hours after thrombolysis [9-11]. The immediate response to thrombolysis varies by patient. While some have shown significant improvement after treatment, others have derived fewer benefits. In this study, we chose 24 hours and 7 days as our endpoints for investigation of the multiple clinical data associated with early neurological improvement of intravenous rt-PA treatment in AIS patients.

\section{Methods}

\section{Participants}


A total of 236 AlS patients given rt-PA thrombolytic therapy (dose of $0.9 \mathrm{mg} / \mathrm{kg}$, but not more than $90 \mathrm{mg}$, of which $10 \%$ was given by intravenous injection, leaving $90 \%$ to be delivered by intravenous drip over a period of $60 \mathrm{~min}$ ) in The Second Affiliated Hospital, Zhejiang University School of Medicine from January 2013 to August 2016 were enrolled. This study was approved by the hospital's institutional ethics committee. Due to the retrospective nature of the study, informed consent was waived..

\section{Inclusion criteria}

(1) Age 18-80; (2) Intravenous thrombolysis with rt-PA treatment within $4.5 \mathrm{~h}$ of stroke onset; (3) Clinical diagnosis of acute ischemic stroke, confirmed by computed tomography (CT) scans or magnetic resonance imaging (MRI); (4) the National Institutes of Health Stroke Scale (NIHSS) score between 4 and 25; posterior circulation stroke is not subject to this limitation; (5) No evidence of intracerebral or subarachnoid hemorrhage by CT.

\section{Exclusion Criteria}

(1) Transient ischemic attack (TIA), cerebral hemorrhage or a history of intracranial hemorrhage in the past 6 months; (2) Oral anticoagulant (INR > 1.5); (3) Onset time of stroke could not be determined; (4) Refractory hypertension (Systolic blood pressure $\geq 185 \mathrm{mmHg}$, or diastolic blood pressure $\geq 110$ $\mathrm{mmHg}$ ); (5) Blood glucose <2.8 mmol/L or $>22.0 \mathrm{mmol} / \mathrm{L}$; (6) Accompanying neurologic or psychiatric disorder, or any terminal illness.

\section{Risk factors}

Data for baseline assessment was collected from hospital discharge reports, including age, sex, weight, previous history of hyperlipidemia, hypertension, diabetes, and alcohol abuse. Alcohol abuse was considered as drinking $\geq 20 \mathrm{~g}$ per day on average. Clinical data included systolic and diastolic blood pressure, blood glucose, fibrinogen, glycosylated hemoglobin, low-density lipoprotein cholesterol (LDL-C), total cholesterol (TC), high-density lipoprotein cholesterol (HDL-C), triglycerides (TG), homocysteic acid levels, time from onset to thrombolysis, and intravenous rt-PA dose. Atrial fibrillation (AF) was diagnosed when its presence was documented in medical records, or it was diagnosed at stroke by conventional electrocardiogram, dynamic electrocardiogram or electrocardiogram monitoring. Hemorrhagic transformation and symptomatic intracranial hemorrhage $24 \mathrm{~h}$ after thrombolysis assessment referred to the European Cooperative Acute Stroke Study (ECASS) $\otimes$ standard.

\section{Stroke severity and outcome measures}

Stroke severity was assessed with NIHSS score by neurologists prior to intravenous thrombolysis. Neurological impairment was evaluated using the NIHSS score at $24 \mathrm{~h}$ and $7 \mathrm{~d}$ after intravenous thrombolysis. Early neurological improvement was defined as a $\geq 4$-point decrease in NIHSS score compared to baseline or a score of 0 or 1 at $24 \mathrm{~h}$ and $7 \mathrm{~d}$; other scores were considered invalid.

\section{Statistical analysis}


SPSS (version 19.0; SPSS Inc., Chicago, IL, USA). was used for all statistical analyses. The risk factors for early neurological improvement were separately tested. Significant variables $(P<0.1)$ identified in univariate analyses were entered in a multivariate logistic regression model for further analysis. Odds ratios (ORs) and $95 \%$ confidence intervals (Cls) were presented. Early neurological improvement was coded as a ordinal parameter (invalid, 0 ; efficacy, 1). P $<0.05$ was considered statistically significant.

\section{Results}

A total of 236 patients with AIS received intravenous rt-PA thrombolysis, of which 11 patients had an NIHSS score less than 4 on admission, 10 patients had arterial embolectomy, and there were 6 patients with incomplete data. The remaining 209 patients were enrolled, of which 84 were female. The average age of the patients was $65.2 \pm 13.1$ years old. The average NIHSS score was $10.7 \pm 5.5$ at baseline, and the average treatment time was $170 \pm 59.4 \mathrm{~min}$.

A total of 74 patients showed early neurological improvement $24 \mathrm{~h}$ after intravenous thrombolysis with rtPA, and 127 patients showed neurological improvement $7 \mathrm{~d}$ after intravenous thrombolysis with rt-PA. Patients with poor outcomes had higher levels of blood lipids (including TC, LDL), inflammatory factors (C-reactive protein) and higher rates of AF. Patient characteristics for all patients and those with early neurological improvement at $24 \mathrm{~h}$ and $7 \mathrm{~d}$ are shown in Table 1. Patients who had early neurological improvement at $7 \mathrm{~d}$ after thrombolysis also had shorter treatment to onset times (164 $\pm 61 \mathrm{~min}$ vs $179 \pm$ $56 \mathrm{~min}$ ). The results from the multivariate ordinal logistic regression analysis are summarized in Table 2. Non-AF (OR $=2.092,95 \%$ Cl: $1.098 \sim 3.985 ; \mathrm{P}=0.02)$ was independently associated with early neurological improvement at $24 \mathrm{~h}$. Non-AF $(\mathrm{OR}=2.832,95 \% \mathrm{Cl}: 1.458 \sim 5.501 ; \mathrm{P}=0.002)$ and treatment to onset time $(\mathrm{OR}=0.994,95 \% \mathrm{Cl}: 0.989 \sim 1.000 ; \mathrm{P}=0.036)$ were independently associated with early neurological improvement at $7 \mathrm{~d}$ (Table 2).

A total of 7 patients (3.35\%) had spontaneous intracerebral hemorrhage ( $\mathrm{sICH})$ after thrombolysis. These patients had higher systolic and diastolic blood pressure, higher baseline NIHSS scores, and higher rates of AF. Baseline NIHSS score and diastolic blood pressure were independently associated with sICH (Table 3).

\section{Discussion}

Non-AF was independently associated with early neurological improvement at both $24 \mathrm{~h}$ and $7 \mathrm{~d}$ after intravenous thrombolysis in our study. The group with the best outcome had fewer patients with a previous history of AF or diagnosis of AF at stroke. Our results are consistent with previous studies showing poorer outcomes among AIS patients with AF receiving thrombolysis [12-15]. Others have found that AF patients show no observable benefit after thrombolysis, even if their thrombolytic therapy was similar when compared with non-AF patients [16]. The adverse impact of AF is likely attributable to larger areas of hypoperfusion and lower recanalization, leading to larger infarct volumes, more severe hemorrhagic transformation and worse stroke outcome [17]. However, a 3035 case report showed that AF 
patients had a similar outcome after thrombolysis when compared with non-AF patients [18]. Some research even indicates that $A F$ is a good predictor of outcome 3 months after thrombolysis in patients with severe stroke [19]. One possible reason is that AIS patients with AF often form red thrombus in the intracranial arteries, which are composed of red blood cells and fibrous proteins. Animal studies have shown that red thrombus show increased sensitivity to rt-PA and are more likely to be dissolved. Whether AIS patients with AF benefit from thrombolytic therapy or not is controversial, and more research is needed.

We found that treatment to onset time was independently associated with early neurological improvement at $7 \mathrm{~d}$. The benefit of rt-PA was thought to be due to vessel recanalization, resulting in restitution of blood flow to ischemic regions of brain. The improvement of early neurological dysfunction indicated recanalization of the occlusive vessels, which is highly correlated with a good long-term prognosis [20,21]. In our study, patients who showed early neurological improvement had shorter onset to treatment time compared to those without early neurological improvement.

Patients without early neurological improvement had higher levels of blood lipids (including TC, LDL) and inflammatory factor (C-reactive protein, CRP). However, they showed no significant difference in the multiplicity analysis, possibly due to other confounding factors. There have been reports that blood lipids and CRP are factors associated with stroke and stroke outcome [22-24], but whether they are independently associated with early neurological improvement needs further exploration.

In our study, there were 7 patients (3.35\%) with hemorrhage after thrombolytic therapy. After a singlefactor analysis, it was found that the baseline NIHSS and diastolic blood pressure (DBP) were risk factors for $\mathrm{sICH}$ after thrombolysis. We did not do a multiplicity analysis due to the sample size $(\mathrm{N}=7)$. A study with a total of 31627 patients treated with intravenous rt-PA has shown that baseline NIHSS is an independent risk factor for $\mathrm{sICH}$ and that the overall rate of $\mathrm{SICH}$ is 1.8\% [25]. AIS Patients with high baseline NIHSS score had a greater risk of sICH and a worse outcome. A study from Germany and Slovakia indicated that significantly increased blood pressure (SBP > $185 \mathrm{mmHg}$ or DBP $>110 \mathrm{mmHg}$ ) was common in stroke patient before and during intravenous thrombolysis, but could not predict cerebral hemorrhage or sICH [26]. The current study demonstrated that systolic blood pressure was independently associated with sICH [27]; however, due to the sample size, whether DBP was associated with sICH could not be determined and needs further study.

This study has several limitations. First, our small sample size may lower the power enough to impact our ability to detect predictive relationships between early neurological improvement and other factors; a larger number of patients will be used in future research. Second, we did not follow up at $90 \mathrm{~d}$. Instead we chose $24 \mathrm{~h}$ and $7 \mathrm{~d}$ as our endpoints because $7 \mathrm{~d}$ NIHSS is a sensitive outcome measure for exploratory clinical trials in acute stroke [28]. Finally, we did not use prolonged noninvasive cardiac rhythm monitoring, which may increase AF detection among AIS patients. Identifying predictors of early neurological improvement may help to improve patient selection for interventional therapy and allow for a more accurate estimation of the prognosis. 


\section{Conclusions}

Non-AF was independently associated with early neurological improvement after intravenous thrombolysis in AIS patients, but non-AF was not associated with the occurrence of sICH. Onset to treatment time was a predictive independent factor for early neurological improvement at $7 \mathrm{~d}$ after thrombolysis in AIS patients.

\section{List Of Abbreviations}

AIS, acute ischemic stroke; CT, computed tomography; MRI, magnetic resonance imaging; NIHSS, National Institutes of Health Stroke Scale; TIA, transient ischemic attack; LDL-C, low-density lipoprotein cholesterol; TG, triglycerides; AF, Atrial fibrillation; ECASS, European Cooperative Acute Stroke Study; ORs, odds ratios; Cis, confidence intervals, sICH, intracerebral hemorrhage; CRP, C-reactive protein; DBP, diastolic blood pressure, SBP, systolic blood pressure

\section{Declarations}

\section{Acknowledgments}

None.

\section{Funding}

This study was supported by research grants from the National Natural Science Foundation of China (81573402, 81703479, 81703498 and 81773700), the Health Bureau of Zhejiang Province (2016ZDA009 and WKJ-ZJ-1719). The funders had no role in the study design, data collection and analysis, decision to publish, or in the preparation of the manuscript.

\section{Availability of data and materials}

All data accessed was de-identified which was approved by the ethics committee before the study began. The dataset of the current study is available from the corresponding author upon reasonable request.

\section{Authors' Contributions}

$\mathrm{HD}$ and $\mathrm{HX}$ contributed to conception and design of the study. $\mathrm{HD}$ and JL were involved in gaining ethical approval. JL performed all analyses after discussions with and statistical input from JH. JL wrote the first draft of the manuscript. JL and FI were responsible for data collection. All authors reviewed and edited the manuscript and approved the final version of the manuscript.

\section{Ethics and Consent to participate}

Informed consent was not required by local institutional review boards (IRBs) due to subject anonymity and minimal risk to participants. Use of the registry database and additional medical data was also 
approved by the Second Affiliated Hospital, Zhejiang University School of Medicine (SAHZU) IRBs (No. 2012-036).

Consent for publication

Not applicable.

Competing interests

The authors declare that they have no competing interests.

\section{References}

1. Global, regional, and national age-sex specific all-cause and cause-specific mortality for 240 causes of death, 1990-2013: a systematic analysis for the Global Burden of Disease Study 2013. Lancet 2015, 385(9963):117-171.

2. El-Koussy M, Schroth G, Brekenfeld C, Arnold M: Imaging of acute ischemic stroke. Eur Neurol 2014, 72(5-6):309-316.

3. Hacke W, Kaste M, Bluhmki E, Brozman M, Davalos A, Guidetti D, Larrue V, Lees KR, Medeghri Z, Machnig T et al: Thrombolysis with alteplase 3 to 4.5 hours after acute ischemic stroke. The New England journal of medicine 2008, 359(13):1317-1329.

4. Wahlgren N, Ahmed N, Davalos A, Hacke W, Millan M, Muir K, Roine RO, Toni D, Lees KR: Thrombolysis with alteplase 3-4.5 $\mathrm{h}$ after acute ischaemic stroke (SITS-ISTR): an observational study. Lancet 2008, 372(9646):1303-1309.

5. Liao XL, Wang CX, Wang YL, Wang CJ, Zhao XQ, Zhang LQ, Liu LP, Pan YS, Wang YJ: Implementation and outcome of thrombolysis with alteplase 3 to $4.5 \mathrm{~h}$ after acute stroke in Chinese patients. CNS Neurosci Ther 2013, 19(1):43-47.

6. Khatri P, Abruzzo T, Yeatts SD, Nichols C, Broderick JP, Tomsick TA: Good clinical outcome after ischemic stroke with successful revascularization is timedependent. Neurology 2009, 73(13):1066-1072.

7. Eryildiz ES, Ozdemir AO: Factors Associated with Early Recovery after Intravenous Thrombolytic Therapy in Acute Ischemic Stroke. Noro Psikiyatr Ars 2018, 55(1):80-83.

8. Yeo LL, Paliwal P, Teoh HL, Seet RC, Chan BP, Wakerley B, Liang S, Rathakrishnan R, Chong VF, Ting EY et al: Early and continuous neurologic improvements after intravenous thrombolysis are strong predictors of favorable long-term outcomes in acute ischemic stroke. J Stroke Cerebrovasc Dis 2013, 22(8):e590596. 
9. Kvistad CE, Thomassen L, Waje-Andreassen U, Logallo N, Naess H: Body temperature and major neurological improvement in tPA-treated stroke patients. Acta Neurol Scand 2014, 129(5):325-329.

10. Yaghi S, Hinduja A, Bianchi N: Predictors of major improvement after intravenous thrombolysis in acute ischemic stroke. Int J Neurosci 2016, 126(1):67-69.

11. Chen J, Zhang Z, Chen L, Feng X, Hu W, Ge W, Li X, Jin P, Shao B: Correlation of Changes in Leukocytes Levels 24 Hours after Intravenous Thrombolysis With Prognosis in Patients With Acute Ischemic Stroke. J Stroke Cerebrovasc Dis 2018, 27(10):2857-2862.

12. Seet RC, Zhang Y, Wijdicks EF, Rabinstein AA: Relationship between chronic atrial fibrillation and worse outcomes in stroke patients after intravenous thrombolysis. Arch Neurol 2011, 68(11):1454-1458.

13. Awadh M, MacDougall N, Santosh C, Teasdale E, Baird T, Muir KW: Early recurrent ischemic stroke complicating intravenous thrombolysis for stroke: incidence and association with atrial fibrillation. Stroke 2010, 41(9):1990-1995.

14. Yue R, Li D, Yu J, Li S, Ma Y, Huang S, Zeng Z, Zeng R, Sun X: Atrial Fibrillation is Associated With Poor Outcomes in Thrombolyzed Patients With Acute Ischemic Stroke: A Systematic Review and MetaAnalysis. Medicine (Baltimore) 2016, 95(10):e3054.

15. Findler M, Molad J, Bornstein NM, Auriel E: Worse Outcome in Patients with Acute Stroke and Atrial Fibrillation Following Thrombolysis. Isr Med Assoc J 2017, 19(5):293-295.

16. Saposnik G, Gladstone D, Raptis R, Zhou L, Hart RG: Atrial fibrillation in ischemic stroke: predicting response to thrombolysis and clinical outcomes. Stroke 2013, 44(1):99-104.

17. Tu HT, Campbell BC, Christensen S, Desmond PM, De Silva DA, Parsons MW, Churilov L, Lansberg MG, Mlynash $\mathrm{M}$, Olivot JM et al: Worse stroke outcome in atrial fibrillation is explained by more severe hypoperfusion, infarct growth, and hemorrhagic transformation. Int J Stroke 2015, 10(4):534-540.

18. Sandercock P, Wardlaw JM, Lindley RI, Dennis M, Cohen G, Murray G, Innes K, Venables G, Czlonkowska A, Kobayashi A et al: The benefits and harms of intravenous thrombolysis with recombinant tissue plasminogen activator within $6 \mathrm{~h}$ of acute ischaemic stroke (the third international stroke trial [IST3]): a randomised controlled trial. Lancet 2012, 379(9834):2352-2363.

19. Sung SF, Chen YW, Tseng MC, Ong CT, Lin HJ: Atrial fibrillation predicts good functional outcome following intravenous tissue plasminogen activator in patients with severe stroke. Clin Neurol Neurosurg 2013, 115(7):892-895.

20. Kharitonova TV, Melo TP, Andersen G, Egido JA, Castillo J, Wahlgren N, investigators S: Importance of cerebral artery recanalization in patients with stroke with and without neurological improvement after intravenous thrombolysis. Stroke 2013, 44(9):2513-2518. 
21. Skagen K, Skjelland M, Russell D, Jacobsen EA: Large-Vessel Occlusion Stroke: Effect of Recanalization on Outcome Depends on the National Institutes of Health Stroke Scale Score. J Stroke Cerebrovasc Dis 2015, 24(7):1532-1539.

22. Xu T, Zhang JT, Yang M, Zhang H, Liu WQ, Kong Y, Xu T, Zhang YH: Dyslipidemia and outcome in patients with acute ischemic stroke. Biomed Environ Sci 2014, 27(2):106-110.

23. Irimie CA, Varciu M, Irimie M, Ifteni PI, Minea DI: C-Reactive Protein and T3: New Prognostic Factors in Acute Ischemic Stroke. J Stroke Cerebrovasc Dis 2018, 27(10):2731-2737.

24. Zheng X, Zeng N, Wang A, Zhu Z, Zhong C, Xu T, Xu T, Peng Y, Peng H, Li Q et al: Elevated C-reactive Protein and Depressed High-density Lipoprotein Cholesterol are Associated with Poor Function Outcome After Ischemic Stroke. Curr Neurovasc Res 2018, 15(3):226-233.

25. Mazya M, Egido JA, Ford GA, Lees KR, Mikulik R, Toni D, Wahlgren N, Ahmed N: Predicting the risk of symptomatic intracerebral hemorrhage in ischemic stroke treated with intravenous alteplase: safe Implementation of Treatments in Stroke (SITS) symptomatic intracerebral hemorrhage risk score. Stroke 2012, 43(6):1524-1531.

26. Kellert L, Rocco A, Sykora M, Hacke W, Ringleb PA: Frequency of increased blood pressure levels during systemic thrombolysis and risk of intracerebral hemorrhage. Stroke 2011, 42(6):1702-1706.

27. Kellert L, Hametner C, Ahmed N, Rauch G, MacLeod MJ, Perini F, Lees KR, Ringleb PA: Reciprocal Interaction of 24-Hour Blood Pressure Variability and Systolic Blood Pressure on Outcome in Stroke Thrombolysis. Stroke 2017, 48(7):1827-1834.

28. Kerr DM, Fulton RL, Lees KR: Seven-day NIHSS is a sensitive outcome measure for exploratory clinical trials in acute stroke: evidence from the Virtual International Stroke Trials Archive. Stroke 2012, 43(5):1401-1403.

\section{Tables}

Table 1 Risk factors for early efficacy of intravenous thrombolysis at 24 hours and 7 days after treatment 


\begin{tabular}{|c|c|c|c|c|c|c|c|}
\hline & total & 24 hours & & & 7 days & & \\
\hline Characteristics & $\mathrm{n}=209$ & $\begin{array}{l}\text { Efficacy } \\
(n=74)\end{array}$ & $\begin{array}{l}\text { Invalid } \\
(n= \\
135)\end{array}$ & $\begin{array}{l}P \\
\text { value* }\end{array}$ & $\begin{array}{l}\text { Efficacy } \\
(n= \\
127)\end{array}$ & $\begin{array}{l}\text { Invalid } \\
(\mathrm{n}=82)\end{array}$ & $\begin{array}{l}\mathrm{P} \\
\text { Value* }\end{array}$ \\
\hline Sex(male), \% & $125(59.8)$ & $45(60.8)$ & $80(59.3)$ & 0.827 & $77(60.6)$ & $48(58.5)$ & 0.763 \\
\hline Age, y & $\begin{array}{l}65.2 \pm \\
13.1\end{array}$ & $\begin{array}{l}64.2 \pm \\
14.3\end{array}$ & $\begin{array}{l}65.7 \pm \\
12.5\end{array}$ & 0.429 & $\begin{array}{l}65.0 \pm \\
13.7\end{array}$ & $\begin{array}{l}65.4 \pm \\
12.2\end{array}$ & 0.831 \\
\hline Alcohol abuse & $48(23)$ & $18(24.3)$ & $30(22.2)$ & 0.730 & $27(21.3)$ & $21(25.6)$ & 0.465 \\
\hline Hypertension & $141(67.5)$ & $53(71.6)$ & $88(65.2)$ & 0.342 & $84(66.1)$ & $57(69.5)$ & 0.612 \\
\hline Diabetes & $37(17.7)$ & $15(20.3)$ & $22(16.3)$ & 0.472 & 23(18.1) & $14(17.1)$ & 0.848 \\
\hline Hyperlipidemia & $17(8.1)$ & $4(5.4)$ & $13(9.6)$ & 0.285 & $9(7.1)$ & $8(9.8)$ & 0.491 \\
\hline Atrial fibrillation & $80(38.3)$ & $22(29.7)$ & $58(43.0)$ & 0.060 & $42(33.1)$ & $38(46.3)$ & 0.054 \\
\hline $\begin{array}{l}\text { Previous history of } \\
\text { stroke }\end{array}$ & $31(14.8)$ & $8(10.8)$ & 23(17.0) & 0.226 & $18(14.2)$ & 13(15.9) & 0.739 \\
\hline $\begin{array}{l}\text { Systolic blood } \\
\text { pressure, mmHg }\end{array}$ & $154 \pm 24$ & $\begin{array}{l}151 \pm \\
23\end{array}$ & $\begin{array}{l}156 \pm \\
25\end{array}$ & 0.199 & $\begin{array}{l}153 \pm \\
24\end{array}$ & $\begin{array}{l}156 \pm \\
25\end{array}$ & 0.306 \\
\hline $\begin{array}{l}\text { Diastolic blood } \\
\text { pressure, } \mathrm{mmHg}\end{array}$ & $84 \pm 13$ & $83 \pm 12$ & $84 \pm 14$ & 0.618 & $83 \pm 13$ & $86 \pm 13$ & 0.067 \\
\hline $\mathrm{TC}, \mathrm{mmol} / \mathrm{I}$ & $4.3 \pm 1.2$ & $\begin{array}{l}3.5 \pm \\
0.9\end{array}$ & $\begin{array}{l}4.8 \pm \\
1.3\end{array}$ & 0.064 & $\begin{array}{l}4.5 \pm \\
1.0\end{array}$ & $\begin{array}{l}4.9 \pm \\
1.3\end{array}$ & 0.060 \\
\hline $\mathrm{HDL}-\mathrm{C}, \mathrm{mmol} / \mathrm{I}$ & $1.2 \pm 0.3$ & $\begin{array}{l}1.1 \pm \\
0.3\end{array}$ & $\begin{array}{l}1.2 \pm \\
0.3\end{array}$ & 0.290 & $\begin{array}{l}1.2 \pm \\
0.3\end{array}$ & $\begin{array}{l}1.1 \pm \\
0.3\end{array}$ & 0.262 \\
\hline LDL-C, mmol/l & $2.7 \pm 0.9$ & $\begin{array}{l}2.6 \pm \\
0.7\end{array}$ & $\begin{array}{l}2.8 \pm \\
1.0\end{array}$ & $0.041^{*}$ & $\begin{array}{l}2.6 \pm \\
0.8\end{array}$ & $\begin{array}{l}2.9 \pm \\
1.1\end{array}$ & $0.038 *$ \\
\hline $\mathrm{TG}, \mathrm{mmol} / \mathrm{l}$ & $1.4 \pm 0.9$ & $\begin{array}{l}1.3 \pm \\
0.7\end{array}$ & $\begin{array}{l}1.4 \pm \\
1.0\end{array}$ & 0.615 & $\begin{array}{l}1.3 \pm \\
0.8\end{array}$ & $\begin{array}{l}1.5 \pm \\
1.0\end{array}$ & 0.080 \\
\hline $\begin{array}{l}\text { Blood glucose, } \\
\mathrm{mmol} / \mathrm{l}\end{array}$ & $7.6 \pm 3.0$ & $\begin{array}{l}7.5 \pm \\
2.7\end{array}$ & $\begin{array}{l}7.7 \pm \\
3.2\end{array}$ & 0.678 & $\begin{array}{l}7.6 \pm \\
2.8\end{array}$ & $\begin{array}{l}7.7 \pm \\
3.3\end{array}$ & 0.833 \\
\hline $\mathrm{HbA} 1 \mathrm{c}$ & $6.3 \pm 1.4$ & $\begin{array}{l}6.2 \pm \\
1.4\end{array}$ & $\begin{array}{l}6.3 \pm \\
1.4\end{array}$ & 0.505 & $\begin{array}{l}6.2 \pm \\
1.4\end{array}$ & $\begin{array}{l}6.4 \pm \\
1.4\end{array}$ & 0.265 \\
\hline Homocysteic acid & $\begin{array}{l}15.6 \pm \\
9.2\end{array}$ & $\begin{array}{l}16.2 \pm \\
9.8\end{array}$ & $\begin{array}{l}15.2 \pm \\
8.9\end{array}$ & 0.466 & $\begin{array}{l}15.9 \pm \\
9.4\end{array}$ & $\begin{array}{l}15.1 \pm \\
8.9\end{array}$ & 0.567 \\
\hline Fibrinogen & $2.8 \pm 1$ & $\begin{array}{l}2.9 \pm \\
1.0\end{array}$ & $\begin{array}{l}2.8 \pm \\
1.0\end{array}$ & 0.319 & $\begin{array}{l}2.8 \pm \\
1.1\end{array}$ & $\begin{array}{l}2.8 \pm \\
0.9\end{array}$ & 0.834 \\
\hline C-reactive protein & $\begin{array}{l}9.7 \pm \\
20.0\end{array}$ & $\begin{array}{l}6.1 \pm \\
7.6\end{array}$ & $\begin{array}{l}11.6 \pm \\
26.8\end{array}$ & $0.026^{*}$ & $\begin{array}{l}6.9 \pm \\
10.6\end{array}$ & $\begin{array}{l}14.0 \pm \\
32.4\end{array}$ & 0.059 \\
\hline
\end{tabular}




$\begin{array}{llllllll}\begin{array}{l}\text { Treatment to onset } \\ \text { time, min }\end{array} & 170 \pm 59 & \begin{array}{l}167 \pm \\ 62\end{array} & \begin{array}{l}171 \pm \\ 58\end{array} & 0.651 & 164 \pm & 179 \pm & 0.068 \\ \text { Baseline NIHSS } & 10.7 \pm & 10.6 \pm & 10.7 \pm & 0.884 & 10.8 \pm & 10.5 \pm & 0.703 \\ & 5.5 & 5.5 & 5.5 & & 5.2 & 5.8 & \end{array}$

TC indicates total cholesterol; HDL-C, high density lipoprotein cholesterol; LDL-C, low-density lipoprotein cholesterol; TG, triglyceride; HbA1c, glycosylated hemoglobin.

Table 2 Multiplicity analysis of early efficacy of intravenous thrombolysis at 24 hours and 7 days after treatment

\begin{tabular}{|c|c|c|c|c|}
\hline \multirow[t]{2}{*}{$\mathrm{N}$} & \multicolumn{4}{|c|}{ Ordinal Logistic Regression Statistics } \\
\hline & Characteristics & OR & $95 \% \mathrm{Cl}$ & P Value* \\
\hline \multicolumn{5}{|c|}{24 hours } \\
\hline \multirow[t]{4}{*}{74} & Atrial fibrillation & 2.092 & $1.098 \sim 3.985$ & $0.025^{*}$ \\
\hline & $\mathrm{TC}, \mathrm{mmol} / \mathrm{l}$ & 0.867 & $0.437 \sim 1.721$ & 0.683 \\
\hline & LDL-C, mmol/l & 0.867 & $0.339 \sim 1.930$ & 0.633 \\
\hline & C-reactive protein & 0.977 & $0.948 \sim 1.007$ & 0.129 \\
\hline \multicolumn{5}{|c|}{7 days } \\
\hline \multirow[t]{7}{*}{127} & Atrial fibrillation & 2.832 & $1.458 \sim 5.501$ & $0.002^{\star}$ \\
\hline & Diastolic blood pressure, $\mathrm{mmHg}$ & 0.979 & $0.956 \sim 1.003$ & 0.086 \\
\hline & $\mathrm{TC}, \mathrm{mmol} / \mathrm{l}$ & 1.144 & $0.556 \sim 2.354$ & 0.714 \\
\hline & LDL-C, mmol/l & 0.583 & $0.239 \sim 1.425$ & 0.237 \\
\hline & $\mathrm{TG}, \mathrm{mmol} / \mathrm{l}$ & 0.730 & $0.505 \sim 1.055$ & 0.094 \\
\hline & C-reactive protein & 0.982 & $0.962 \sim 1.003$ & 0.095 \\
\hline & Treatment to onset time, min & 0.994 & $0.989 \sim 1.000$ & $0.036^{\star}$ \\
\hline
\end{tabular}

TC indicates total cholesterol; LDL-C, low density lipoprotein cholesterol; TG, triglyceride; OR, odds ratio; $\mathrm{Cl}$, confidence interval.

Table 3 Risk factors for sICH after intravenous thrombolysis 


\begin{tabular}{llll} 
& sICH & non-sICH & P Value* \\
& $(\mathrm{n}=7)$ & $(\mathrm{n}=202)$ & \\
\hline Sex (male), \% & $2(28.6)$ & $123(60.9)$ & 0.089 \\
\hline Age, y & $69.4 \pm 8.4$ & $65.0 \pm 13.2$ & 0.381 \\
\hline Alcohol abuse & $0(0)$ & $48(23.8)$ & 0.054 \\
\hline Hypertension & $4(57.1)$ & $137(67.8)$ & 0.562 \\
\hline Diabetes & $2(28.6)$ & $35(17.3)$ & 0.472 \\
\hline Hyperlipidemia & $0(0)$ & $17(8.4)$ & 0.272 \\
\hline Atrial fibrillation & $5(71.4)$ & $75(37.1)$ & 0.067 \\
\hline Previous history of stroke & $3(42.9)$ & $28(13.9)$ & 0.203 \\
\hline Systolic blood pressure, mmHg & $169 \pm 17$ & $154 \pm 24$ & 0.092 \\
\hline Diastolic blood pressure, mmHg & $93 \pm 19$ & $84 \pm 13$ & $0.048^{\star}$ \\
\hline TC, mmol/l & $5.0 \pm 2.1$ & $4.7 \pm 1.1$ & 0.440 \\
\hline HDL-C, mmol/l & $1.4 \pm 0.5$ & $1.1 \pm 0.3$ & 0.174 \\
\hline LDL-C, mmol/I & $2.8 \pm 2.2$ & $2.7 \pm 0.9$ & 0.902 \\
\hline TG, mmol/l & $1.4 \pm 1.1$ & $1.4 \pm 0.9$ & 0.942 \\
\hline Blood glucose, mmol/I & $8.4 \pm 2.7$ & $7.6 \pm 3.0$ & 0.474 \\
\hline HbA1c & $6.9 \pm 2.1$ & $6.2 \pm 1.4$ & 0.237 \\
\hline Homocysteic acid & $13.1 \pm 7.3$ & $15.7 \pm 9.3$ & 0.479 \\
\hline Fibrinogen & $2.8 \pm 0.4$ & $2.8 \pm 1.0$ & 0.909 \\
\hline C-reactive protein & $21.6 \pm 20.1$ & $9.2 \pm 22.1$ & 0.146 \\
\hline Treatment to onset time, min & $193 \pm 54$ & $169 \pm 60$ & 0.300 \\
\hline Baseline NIHSS & $15.6 \pm 5.8$ & $10.5 \pm 5.4$ & $0.015^{\star}$ \\
\hline
\end{tabular}

TC indicates total cholesterol; HDL-C, high-density lipoprotein cholesterol; LDL-C, low-density lipoprotein cholesterol; TG, triglyceride; HbA1c, glycosylated hemoglobin; sICH, spontaneous intracerebral hemorrhage. 